Archives de sciences sociales des religions

138 | avril - juin 2007

Varia

Danièle Dehouve, Essai sur la royauté sacrée en

République mexicaine

Paris, Éditions du CNRS, 2006, 147 p.

Véronique Duchesne

CpenEdition

Journals

Édition électronique

URL : http://journals.openedition.org/assr/5922

DOI : $10.4000 /$ assr.5922

ISSN : $1777-5825$

Éditeur

Éditions de l'EHESS

Édition imprimée

Date de publication : 1 juin 2007

Pagination : $97-251$

ISBN : 978-2-7132-2143-9

ISSN : 0335-5985

Référence électronique

Véronique Duchesne, «Danièle Dehouve, Essai sur la royauté sacrée en République mexicaine », Archives

de sciences sociales des religions [En ligne], 138 | avril - juin 2007, document 138-30, mis en ligne le 11 septembre 2007, consulté le 21 septembre 2020. URL : http://journals.openedition.org/assr/5922

DOI : https://doi.org/10.4000/assr.5922

Ce document a été généré automatiquement le 21 septembre 2020

(C) Archives de sciences sociales des religions 


\title{
Danièle Dehouve, Essai sur la royauté sacrée en République mexicaine
}

Paris, Éditions du CNRS, 2006, 147 p.

\author{
Véronique Duchesne
}

1 Sous un titre un brin provocateur, ce que l'auteur reconnaît dès les premières lignes, cet essai est une analyse fine et détaillée d'un concept très connu en ethnologie mais jusqu'alors non retenu pour parler des sociétés indiennes étudiées par l'auteur. Les théories classiques parlent en effet du "système des charges " indien (aussi appelé "hiérarchie civile et religieuse ", "système de cargos" ou "échelle de coût et de prestige »), que l'on retrouve dans de nombreuses communautés indiennes du Mexique et de l'Amérique centrale, soit dans l'ancienne Mésoamérique (définie par les archéologues en fonction de certains traits tels que l'agriculture d'irrigation, l'architecture monumentale, un type de calendrier). L'organisation sociale y est structurée par des ensembles de postes administratifs et rituels, des charges qu'occupent les hommes, selon un système hiérarchique en apparence. Ces charges visent le respect des rituels qui soudent la communauté et l'organisation des fêtes, d'où des dépenses. Elles ont donc un double aspect religieux et économique, que trop de travaux distinguent soigneusement des fonctions politiques.

2 À partir de sa longue expérience de terrain (principalement chez les Indiens du Guerrero, au Mexique, depuis la fin des années 1960), Danièle Dehouve a constaté les nombreuses inconsistances du modèle, qui prend rarement en compte d'autres fonctions secondaires, et minimise les imbrications du politique et du rituel. Elle note, en effet, l'importance du jeûne avant la prise de fonction, ou le caractère sacré des symboles du pouvoir. Ceci la conduit à effectuer un retour critique sur les modèles classiques du "système des charges" (chap. I) pour ensuite (chap. II) explorer les théories sur la royauté sacrée. La royauté sacrée est d'abord distinguée de la royauté de droit divin (comme ce fut le cas en Occident des rois du Moyen Âge installés dans la gestion des affaires terrestres par une Église catholique qui se réservait le commerce avec Dieu) et de la monarchie absolue. Pour définir le "système de royauté sacrée ", l'auteur reprend principalement l'analyse théorique de A.-M. Hocart (développée dans 
son ouvrage sur les îles Fidji et Ceylan, Rois et courtisans, 1978, $1^{\text {re }}$ éd. en anglais en 1936). Nous retenons que la royauté sacrée est indissociable de la société qu'elle incarne, et porte en elle-même la responsabilité religieuse du fonctionnement social ; un personnage central (ou un ensemble de personnages) cumule le pouvoir et des attributions sacrées; il est garant de la prospérité de la communauté et responsable de l'infortune publique, si bien que la vie de chaque individu prise isolément dépend, en fin de compte, de lui; il est également le sacrifiant principal, censé recueillir les bienfaits des sacrifices au nom du groupe. Dans cette approche théorique, la notion de différentiation des fonctions remplace donc celle de séparation du temporel et du spirituel.

3 Cette imbrication du politique et du religieux, que l'on retrouve dans des communautés du Guerrero, du Chiapas, ou du Yucatan, remonterait à une origine préhispanique, à la royauté aztèque, dont D. Dehouve brosse un rapide portrait (chap. III). La définition de l'auteur, qui au terme de «roi " substitue celui de "personnage central» cumulant certaines fonctions liées à l'obtention de la prospérité collective au moyen du rituel, lui permet de rechercher cette figure dans les républiques d'Indiens constituées après la chute des royautés précolombiennes, après que les Espagnols eurent fait disparaître tous les rois indiens (chap. IV et V).

Dans cet ouvrage, remarquablement synthétique (146 p.) et bien structuré, Danièle Dehouve, anthropologue et ethnohistorienne, réussit à tracer une continuité de la période précolombienne à nos jours en montrant comment ce qu'il est maintenant convenu d'appeler, avec l'auteur, le "modèle mésoaméricain de royauté sacrée » a survécu depuis la Conquête espagnole, durant près de cinq siècles, au sein des États coloniaux puis nationaux. Sa thèse est forte et bien argumentée, le modèle présenté permet, effectivement, d'expliquer des aspects négligés du système étudié. On peut cependant se demander si l'esquisse que brosse l'auteur sur la royauté sacrée aztèque fait aujourd'hui l'unanimité parmi les chercheurs de cette aire culturelle. Cet essai apporte indubitablement un éclairage nouveau sur un aspect des communautés indiennes du Mexique et plus largement de la Mésoamérique, que les modèles anciens n'étaient pas parvenus à expliquer. Il est une contribution de valeur à la connaissance anthropologique portant sur les rapports entre le pouvoir et le sacré, aussi bien que sur la question de la sécularisation. 